\title{
Learning disabilities and ethnicity: achieving cultural competence
}

\section{Jean O’Hara}

Abstract Despite the higher prevalence of learning disabilities among some minority ethnic communities and the greater burden of care, families from minority ethnic communities with a member who has learning disabilities are doubly disadvantaged as a result of racial discrimination and culturally inappropriate forms of care and service provision. This paper looks at the issue of discrimination, as well as the generally negative attitudes towards people with learning disabilities, and synthesises these into the concept of 'double jeopardy'. It concludes by proposing ways of developing cultural competence in the delivery of care to this population.

Enormous cultural complexity is found in modernday families. Spouses may belong to different racial, religious or ethnic groups, and two or more cultures may be represented among the parents and children (Falicov, 1995). Relying on potentially stereotyped and ethnically focused information can be very misleading. Individuals vary considerably in the extent to which they choose to observe religious or cultural customs and conventions; the degree of acculturation may also vary between generations and between men and women. However, there is no doubt that the stigma of learning disability ('mental retardation') can be shattering and it transcends race, beliefs and culture. It creates profound emotional, practical and psychological experiences for all parents (Shah, 1992).

\section{The "minority experience"}

Ethnicity is a complex concept which includes religious and cultural background, shared histories and common descent. Ultimately, it is the individual's psychological sense of belonging. Although not unique to families from ethnic minorities, there are distinguishing life events that differentiate the 'minority experience' from that of White middleclass families (Sue \& Sue, 1999; Box 1).

The notion of 'White supremacy' has dominated the social and political landscape in much of the world since the 19th century and it has fuelled exploitation and racism. At the same time, its
Box 1 The minority experience (adapted from Sue \& Sue, 1999)

Ethnic minority reality - often racism and poverty dominate lives.

Conflicting value systems - almost all ethnic minority groups place greater value on families, historical lineage and the submergence of self for the good of the family.

Biculturalism - many families inherit two cultural traditions. It is important to understand how biculturalism influences family structure, communication and dynamics. There is a need to understand the acculturation process.

Minority status - memories of colonialism, imperialism, slavery and the Holocaust, refugee and immigration status, skin colour and obvious physical differences are important factors that may determine the treatment of individuals and their families.

Migration - whether forced or voluntary

Language - many minority families may not possess vocabulary equivalent to standard English and may appear 'flat', 'non-verbal', 'uncommunicative' or 'lacking in insight'.

Social class - aspects of wealth, name, occupation and status.

'scientific' justification in terms of skin colour, skull size and level of intelligence began to emerge.

Jean $\mathrm{O}^{\prime}$ Hara is a consultant in the psychiatry of learning disabilities for East London and the City Mental Health Trust (130A Sewardstone Road, Bethnal Green, London E2 9HN, UK) and an honorary senior clinical lecturer with Queen Mary and Westfield College, London. Since 1992, she has worked in Tower Hamlets, a deprived inner-city London borough with a large ethnic minority population. 
Fernando (1989) describes racism as much more than just prejudice with social consequences. Once racism is embedded within the structures of society, the prejudice of individuals is no longer the main problem: more damaging is the issue of 'institutionally generated inequality'. Direct racial attack is less common than are perceived discrimination in interpersonal communication and inequity in the receipt of services and justice (Chakraborty \& McKenzie, 2002). Studies of Asian families that include someone with a learning disability reveal a deprived, isolated group who suffer racial abuse, encounter language barriers and experience significant levels of stress but have little knowledge or understanding of learning disability (Nadirshaw, 1997). Although there is little information on the needs of other minority ethnic groups, the literature suggests that, despite formal health policy statements, families from minority ethnic communities with a member who has learning disabilities are doubly disadvantaged as a result of racial discrimination and culturally inappropriate forms of care and service provision. Ethnic identity per se does not affect health; what does affect it is the daily experience of racism, perceived racism and a discriminatory society (Karlsen \& Nazroo, 2002).

Another significant minority experience is that of migration. Whether voluntary or forced, it is a traumatic life event. It is the uprooting of meaning, with disruption of life-long attachments and external stability (Falicov, 1995). Family disruption continues through separations and reunions, and parents who raise their children in a culture that differs from their own often feel disempowered.

\section{Anthropological perspectives}

Learning disability is a complex label involving interactions between biogenetic and sociocultural factors. The diagnostic criteria are the significant and enduring impairment in social and intellectual functioning evident before adulthood. Deciding on the presence or absence of learning disability requires an arbitrary line to be drawn across a continuum of ability. One measure is the IQ test, yet this was once used to prove the innate inferiority of immigrant populations. Eminent psychologists such as Arthur Jensen and Hans Eysenck supported claims that differences in IQ ratings between 'White people' and 'coloured, primitive people' were due to race, although this view is now strongly opposed by many (Fernando, 1989).

The cultural bias of IQ testing is well recognised but it is still administered in a culture-blind fashion. Cultural bias in verbal tests is obvious, but there is no guarantee that non-verbal tests are free from bias
(Fernando, 1989). How well children with mild learning disabilities do in school or in adult life and, indeed, how they come to be diagnosed in the first place, largely depends on social and cultural conditions. This type of learning disability has been called 'sociocultural' or 'reversible' to emphasise the importance of social and cultural factors. Ramey et al (1978) showed in the USA that it was possible to identify children who would need special education before or during their school years, solely on information given on their birth certificates. The children most at risk were male, Black and had been born illegitimately to mothers with little formal education.

\section{Society's views}

'In our country, we would not be allowed to treat cattle like that. Perhaps you cannot treat cattle this way in your country either - cattle, after all, are useful, while the retarded are not' (N.E. Bank-Mikkelson, on visiting a state hospital in the USA; quoted in Edgerton, 1984: p. 28).

The neglect and ill-treatment of people with learning disabilities probably exhibits one of the worst histories for any group in society (Sperlinger, 1997). Western reactions have often been brutal. Those with learning disabilities have been killed, kept to entertain guests (a Roman practice that subsequently became common in the courts of European royalty), exhibited as freaks for profit, threatened with eradication and put at risk for the good of others, as in early trials of the measles vaccine. More compassionate views, tempered with pity, horror and contempt, prevailed through the 19th century, with Western attempts to provide institutional treatment and training.

There is little in the literature on the views of nonWestern societies of the past. It was assumed that life in such societies was so simple that people with mild learning disabilities would be unexceptional members of their community, whereas the more severely disabled would be killed early in life. However, cross-cultural evidence indicates that even those with very mild learning disabilities were recognised throughout the world. There was a great variation in the treatment they received (Edgerton, 1984): although some societies inflicted casual cruelties others, including many in Central Asia, India and the Middle East, offered such persons protected and favoured roles.

\section{Cultural and religious attitudes}

Cultural and religious attitudes, understanding and beliefs all play their part in how care is ultimately sought, planned, accepted and delivered. Early 
research interest focused on the attitude of White middle-class parents within a Judaeo-Christian faith. The birth of a child with learning disabilities either stimulated a greater faith or resulted in a complete loss of faith. Some believed that they were being punished for their sins. Fatimilehin \& Nadirshaw (1994) found the variations in attitude between Asian and White British families to be related to cultural and religious differences rather than to any descriptive characteristics of the parent or their child (Box 2). Some would argue that South Asian cultures are more accommodating of people with disabilities (McGrother et al, 2002)

Many non-Western medical systems do not differentiate between physical and mental states, and the spiritual and supernatural elements are intertwined. The Hindu belief in the concept of karma - the cycle of reward and punishment for all deeds and thoughts as the immortal spirit is reborn into another body - may provide an understanding for what has happened and lead to a sense of resignation or acceptance. Middle Eastern cultures regard disability

Box 2 Differences in attitudes and beliefs of Asian and White British families

Fatimilehin \& Nadirshaw (1994) reported the following differences in a cross-cultural study of Asian and White British families

Asian British families

Had more contact with a 'holy' person $(P<0.05)$

Were less aware of what their child's problem is called $(P<0.01)$

Believed in a spiritual explanation/cause for their child's learning disability $(P<0.05)$

Fifty per cent said that they did not know the cause of their child's learning disability

Believed that religion had something particular to say about learning disability $(P<0.005)$

Their faith helped them to cope but offered little social or practical support

Wanted care to be provided by a relative when they were no longer able to provide it themselves $(P<0.01)$

White British families

Most received a medical explanation for their child's disability

None offered a spiritual explanation for their child's disability

Only one felt that it did not know the cause of the child's learning disability

Religion/faith offered social support

Most wanted their child to be cared for in a community home provided by statutory/ voluntary services $(P<0.05)$ as a punishment from heaven, emanating from the spirits or caused by an evil eye (Aminidav \& Weller, 1995). Many Chinese people believe in fate and use a coping strategy of forbearance, seeking supernatural power and praying to ancestors (Cheng \& Tang, 1995). Clinicians have often cited fatalism and the search for a cure as reasons why families from some ethnic minority communities are not interested in educational or habilitative programmes for learning disability. It is frequently assumed that Asian parents do not have a positive or encouraging attitude towards disability, precisely because of their religious or superstitious beliefs (Shah, 1992).

An important misconception about learning disability held by Asian parents is the notion of curability and that the marriage of the person with a learning disability may alleviate the condition. Channabasavanna et al (1985) found that neither the severity of disability nor the socio-economic status of the parents had any effect on this attitude. Rather, it was knowledge of the concept of learning disability, gained through counselling, that was most influential. An example of good practice in this area is provided by Davis \& Rushton (1991).

\section{Gender and social roles}

\footnotetext{
'A woman's Heaven is at her husband's feet' (traditional Asian saying).
}

Social and gender roles and, in particular, traditional female roles, are interpreted differently, in different communities, across generations and within individual families. In 19th-century English literature, men with learning disabilities were portrayed as lacking an essential component of masculine identity, usually because of their inability to handle money (McDonagh, 2000). Women with learning disabilities embodied a paradox, being seen as threatening because of their 'undisciplined sexuality', yet also sexually innocent and in need of protection. This view resulted in mandatory sterilisation and prohibition from marriage. Both practices were still in force in 24 states in the USA as recently as 1971 .

Bengali parents' desire to see their children with learning disabilities married is at the heart of their parental responsibility, and services struggle with the ethical issues this situation may pose (O'Hara \& Martin, 2003). However, securing a marriage partner also serves to reassure and provide comfort to parents that their child will be cared for after their own deaths.

Marriage between close biological relatives is generally regarded with suspicion and distaste within Western society (Bittles, 2001). By comparison, other populations perceive marriage outside the family as a risky and disruptive option. 
In some communities, consanguineous (first-cousin) marriages continue to account for $33 \%-53 \%$ of the total (Jaber et al, 2000). Professionals often relate disability explicitly to consanguineous marriage and they may be unsympathetic because they consider the condition to be self-inflicted. An Asian mother of a child with a learning disability said:

'the first thing he [the general practitioner] asks is, "Is it a first-cousin marriage? You've had one disabled child, then another." He's a good doctor, but, because of his attitude, I only go when I really have to' (Katbamna et al, 2002).

Asian women are seen as isolated because of their traditional customs; the failure by Asians to take up services provided by statutory bodies is attributed to their lack of skills relating to Western lifestyles (Fernando, 1989). Women with learning disabilities face 'triple jeopardy' in relation to race, disability / impairment and gender (Mir et al, 2001). They may experience simultaneous discrimination and disadvantage and have additional support needs in terms of their sexuality and motherhood. However, there is a growing interest in the health and welfare of women with learning disabilities, as evidenced in Walsh \& Heller (2002).

\section{Learning disability in ethnic minority communities}

The prevalence of learning disabilities among South Asians is three times that in majority communities. Of these families, $19 \%$ have more than one member with a learning disability (Mir et al, 2001). Unfortunately, prevalence within other minority ethnic communities, and even for different subgroups within the South Asian community, is not well documented. This higher prevalence has been linked to high levels of maternal and social deprivation combined with factors such as inequality in health care (Emerson, 1997). The health care that is offered may be culturally inappropriate, unwelcoming and discriminatory, with a culture-blaming attitude. It may also have poor standards of communication and offer poor quality of care (Mir et al, 2001). For example, prenatal diagnosis is sometimes withheld from Muslim families on the assumption that they will not consider a termination of pregnancy. This denies them information and choice.

There are reports of ethnic differences in the rate of detection of trisomy-21 using biochemical markers (e.g. Gilbert et al, 1996), with more false-positives in ethnic minorities, which lead to unnecessary anxiety and invasive investigations.

The method used to break news of impairment/ disability to a family from a minority ethnic community may be particularly poor, with the use of a non-professional interpreter adding to the stress and initiating or perpetuating a cycle of bad health experiences and expectations (e.g. Butt \& Mirza, 1996). An information vacuum exists, in terms of culturally appropriate leaflets or audio-visual material, and the type of information that historically has been made available, for example about hygiene and fertility control, may be translated in a way that implies inferior cultural practices (Mir et al, 2001).

\section{Carers in ethnic minority communities}

In the UK, the burden of care, both socially and financially, is greater for carers from minority ethnic communities compared with their White peers (Butt \& Mirza, 1996). This is due to a number of contributory factors including poverty, poor housing, racism, higher levels of unemployment, low pay, minimum pension rights, reduced benefits because of residence status and inadequate education. For example, spouses of adults with learning disabilities from ethnic minority communities are allowed into the UK on the proviso that they do not claim on the welfare state for the first 5 years. There is evidence that general practitioner (GP) consultation rates in minority ethnic communities are significantly higher than in the majority community, but that these patients are less aware of the existence of specialist services (e.g. Katbamna et al, 2002; McGrother et al, 2002). Psychological and emotional distress may not be recognised, as patients from ethnic minorities tend to present to their GP with somatic symptoms (Nadirshaw, 1997). A discriminatory view is that this is an unsophisticated form of communication (Fernando, 1989). There is also a danger of emphasising people's needs in terms of religion, customs and traditions and overlooking their basic needs for decent housing, access to health care and assistance to claim benefits. Factors such as immigration and the quality of housing available, particularly in inner-city areas, often militate against the supportive network traditionally offered by extended families.

A family's failure to spend time with a member with disabilities might be due to insufficient financial and practical support, but it can be perceived by professionals as a lack of interest or engagement with services.

It is a commonly held view that the hierarchical family structure in many non-Western cultures produces 'stress-ridden relationships', and the very strengths of this organisation are seen as a source of actual and potential weakness (Fernando, 1989). Research often pays little attention to the strengths of such a support network. Understanding of and respect for different family organisations are vital 
to service delivery. Parents may not have sole primary responsibility for looking after their children, as care is shared by a number of adults within the extended family. Extended families may involve grandparents, uncles and aunts, cousins and second cousins and even non-blood 'relatives'. It is important to understand how decisions are made and who has the ultimate authority for making them. In some cultures, out-patient appointments may be seen as a social responsibility, with a large group of family members attending. Likewise, a consultation in the home can often involve the presence of a number of family members. The level of individuals' contacts outside their own ethnic group varies, and this can have profound effects on the perceptions and lifestyles of different generations. Second and third generations may have very different attitudes from their predecessors and this can lead to tension and cultural conflicts within a family. When providing services to families that have a range of different structures and priorities, skills are needed to avoid giving primacy to a particular cultural or ethnic approach (Mir et al, 2001).

\section{Ethnic and racial identity}

Racism and stigma are pervasive in the lives of people with learning disabilities who are from the South Asian community. Azmi et al (1997) found this double discrimination to be a painful reality. However, in their study of such a population, all participants had a strong sense of their ethnic and racial identities and viewed these identities positively. There was a wide variation in the extent to which the 'younger' generation, mostly born in the UK, maintained traditional practices such as arranged marriages, gender roles, family obligations and religious observances. Almost all participants named a religious affiliation matching that of their families, and over $50 \%$ reported active observance of their religion. Sixty-three per cent felt that they were treated badly because of their ethnic group ( $27 \%$ did not respond clearly on this issue) and $57 \%$ also felt that they were treated badly because of their disability (33\% did not respond clearly). Frequently, participants reported abusive behaviour from other people which combined racism and stigma.

An essential part of personal identity is personal appearance, and for some communities it is particularly important to pay attention to cultural factors associated with dress, hair and skin care and personal hygiene. Food is another aspect of basic care where cultural and religious needs might be ignored or inadequately catered for. Behavioural programmes and skills training might be based on White culture, for example teaching someone to use a knife, fork and spoon. Provision of physiotherapy activities such as massage, limb manipulation, dancing and swimming needs to be sensitive to the wishes of the family, especially with regard to modesty and appropriate behaviour. Unless such issues are addressed, people from ethnic minority communities are unlikely to use services that they perceive to be discriminatory.

Knowledge about religious beliefs and cultural practices can enable services to ensure that people with learning disabilities from ethnic minority communities experience a range of relevant cultural events and influences. Recurrent themes reported by carers include the need to meet dietary requirements; provide culturally appropriate activities and same-gender centres; increase the number of staff from minority cultures and the number of bilingual workers throughout mainstream services; and adapt materials in a culturally sensitive way. However, the assumption that a family wants support only from someone of their own culture is often misplaced, as workers from other cultures may be perceived as less intrusive (Mir et al, 2001). The preference for same-gender staff to carry out intimate personal care and support is curiously portrayed as a requirement specific only to certain religions and cultures, when, in fact, it exists to a large extent in all communities. This belief is unhelpful as it suggests that the preference is 'different' or 'special' and it gives the impression of an additional burden on resources (Baxter, 1996).

\section{Importance of language}

'Ethnicity patterns our way of thinking, feeling and behaving. Language is one factor in the elaboration of ethnicity' (de Zulueta, 1990).

Communicating with people in a language other than their first language can affect our sensitivity to their attitudes and values (Shah, 1992). Language structures the meaning of communication and contributes to a sense of belonging (Sue \& Sue, 1999). We think and feel in our first language, and using a second language can block thoughts and emotions (Bhugra, 2002). Bilingual patients can appear less psychotic when interviewed in their second language rather than their first language, as well as remaining protected from anxiety and hidden meanings and feelings (de Zulueta, 1990). In some cases, health practitioners are themselves using a second language in clinical practice and not enough attention has been paid to the resulting implications, especially in the context of psychotherapeutic approaches. The choice of language used in the delivery of health services to bilingual families may not appear neutral to them. It can be perceived as collusion between the clinician and the most fluent family member; it may allow the child to speak freely 
from the parent; and it may be used to track transgenerational alliances. Complexity increases with family size and the degree of bilingualism in each family member (Raval, 1996).

\section{Interpreters: help or hindrance?}

It is unethical and unprofessional to use children to interpret. Interpreting by family members should be avoided because of the possible biases and power relationships within the family (Shah, 1992; Farooq \& Fear, 2003). A very high level of interpreting skills is required, with the interpreter at the apex of a triad:

'the interpreter is the person who makes the link between two different languages and cultures... [who] makes sense of unusual questioning, helps contain feelings' (Raval, 1996).

However, interpreters do not have a professional status and their role within services may be ambiguous. They can be seen solely as interpreters of language or as community workers, link workers, advocates, cultural brokers or cultural consultants. Working effectively with interpreters requires training and is a necessary component of providing a high-quality service (Box 3). It is not a luxury. For clinicians who use interpereters, there is the risk of feeling disempowered and culturally ignorant in front of patients and their families, leading to a sense of therapeutic detachment and a mechanical or stilted interview. They may begin to feel de-skilled, excluded or resentful and hold a lower opinion of the efficacy of their involvement. They may become dependent on the interpreter in order to carry out their role. Patients or carers, however, can feel more reassured about their ability to communicate freely through a trained interpreter when describing religious beliefs (such as ghost possessions), unsatisfactory environmental conditions, mental illness and even abuse, without fear of being ridiculed (Raval, 1996). The interpreter, however, may feel it culturally inappropriate to translate particular language (e.g. verbal abuse or that related to sexual behaviour). Discussion of sexuality is surrounded by taboos, more so in some communities than others. Sometimes questions cannot be translated directly and have to be rephrased to make sense in another language. This can result in a translation that is semantically very different from the question originally asked. It is important, therefore, that a method of joint working with the interpreter is agreed prior to the interview.

\section{Developing cultural competence}

Services must develop a sense of belonging in people from a variety of cultures, so that they feel comfortable
Box 3 Working with interpreters (adapted from Shah, 1992; Nadirshaw, 1997)

Skills of a good interpreter

Fluent communication

Ability to engage with the patient while speaking as directed by someone else

Sensitivity and interpersonal skills

Calm and non-threatening personality

Capacity to offer comfort in discussing personal and emotional issues

Negotiating the interpreter-clinician relationship Insist on mutual briefing and debriefing

Ensure interpreter is well versed in the information needed and in any specific concepts that may be used

Agree a model of joint working, e.g. literal translation or translation reflecting cultural context

Ensure interpreter understands the importance of confidentiality

Check for compatibility, e.g. in linguistic and religious backgrounds

Respect the professionalism of the interpreterdo not be suspicious of the relationship between patient/carer and interpreter

Be patient and open-minded. Ask questions without being intentionally offensive

Observe gender issues, religious and cultural events

Be sensitive to the discrimination that patients / families experience in their everyday lives

about them. Falicov (1995) urges applying a cultural lens to everything we do and taking culture into mainstream thinking, teaching and learning. Cultural knowledge is important, but care must be taken not to apply it in a stereotyped manner (Box 4).

Ethnic matching of the clinician/doctor and patient is neither necessary nor always desirable, but it is essential that clinicians are aware of the interactions between the parties (Bhugra, 2002). These are often influenced by training, experience, social class, world views and knowledge of one another's culture and ethnicity (Table 1). For example, there may be an assumption that the absence of toys scattered around the living room floor during a home visit indicates that parents do not think that toys are important or, more worrying, it may be taken as a sign of neglect or environmental deprivation. The sharing of a parental bed is another culture-bound practice, which may lead to judgemental reactions from practitioners concerned with issues of child protection or adult vulnerability. Criticism, especially in front of others, may be a culture-bound expression of parental concern and the encouragement to better oneself. There is a risk, 


\section{Box 4 The continuum of cultural competence}

Cross et al (1989) identified the following culturally appropriate or inappropriate behaviour in a health care organisation:

Cultural destructiveness - cultural/racial oppression, forced assimilation

Cultural incapacity - discriminatory practices, unchallenged stereotypical beliefs

Cultural blindness - 'We treat everyone the same': this approach ignores cultural strengths. The belief that methods used by the dominant culture are universally applicable can lead to implicit or explicit exclusion of ethnic minority communities

Cultural pre-competence - a false sense of accomplishment; inconsistent policies and practices; practitioners are sensitive to minority issues but these are not an organisational priority

Cultural competence - a vision that reflects multi-culturalism, values diversity and views it as an asset: evidence of continuing attempts to accommodate cultural change; careful attention to the dynamics of difference, realising that equal access is not equal treatment

Cultural proficiency - adding to knowledge-base by conducting research; developing new therapeutic approaches based on cultural considerations; follow-through social responsibility to fight social discrimination and advocate for social diversity

however, that it may be misconstrued as dysfunctional family dynamics. The diagnosis therefore of 'family conflict' may be no more than a racist assumption about family life (Fernando, 1989).

A strategic approach is required to ensure that the needs of people from ethnic minority communities are not forgotten. These needs are complicated by issues of power, race and gender politics but they must not be overlooked just because they affect only 'small numbers' within a given population (Cole, 2002; Box 5).

'Special-needs' initiatives can provide a much needed focus on the issues to be addressed, but they are often structurally disadvantaged, with

Table 1 Value and belief models of worldviews (adapted from Sue \& Sue, 1999)

Component values and beliefs

\begin{tabular}{|c|c|c|}
\hline & Within White culture & Within non-White cultures \\
\hline $\begin{array}{l}\text { The individual } v \text {. } \\
\text { the group }\end{array}$ & $\begin{array}{l}\text { Individualism } \\
\text { Independence and autonomy highly } \\
\text { valued and rewarded }\end{array}$ & $\begin{array}{l}\text { Collectivism } \\
\text { Submergence of self for good of family } \\
\text { Interdependence } \\
\text { Allegiance to family is of primary importance and } \\
\text { takes precedence }\end{array}$ \\
\hline Communication & $\begin{array}{l}\text { Direct eye contact } \\
\text { Verbal, emotional and behavioural } \\
\text { expressiveness } \\
\text { Openness and intimacy } \\
\text { Standard English } \\
\text { 'Horizontal' pattern of communication }\end{array}$ & $\begin{array}{l}\text { Silence indicates respect } \\
\text { Non-verbal communication important } \\
\text { Strong feelings restrained (i.e. anger, love, affection, } \\
\text { frustration) } \\
\text { 'Vertical' pattern of communication }\end{array}$ \\
\hline Time & $\begin{array}{l}\text { Viewed as a commodity } \\
\text { Adherence to time-keeping }\end{array}$ & $\begin{array}{l}\text { Punctuality may be unimportant; things done } \\
\text { according to a rational order and not to deadlines }\end{array}$ \\
\hline Thinking & $\begin{array}{l}\text { Reliance on physical or psychological } \\
\text { healing methods } \\
\text { Dismissive/sceptical of supernatural } \\
\text { explanations } \\
\text { Emphasis on objective, rational and } \\
\text { linear thinking }\end{array}$ & $\begin{array}{l}\text { Reliance on spiritual plane for model of healing } \\
\text { Belief in the spirit world affects circumstances of the } \\
\text { living } \\
\text { Relates to nature ('Mother Earth') }\end{array}$ \\
\hline Status & $\begin{array}{l}\text { Measured by economic possessions, } \\
\text { credentials }\end{array}$ & $\begin{array}{l}\text { Honour and respect gained by sharing and giving; } \\
\text { refusing to accept a gift/invitation can be taken as } \\
\text { an insult }\end{array}$ \\
\hline Family structure & Nuclear family as ideal social unit & $\begin{array}{l}\text { Hierarchical relationships } \\
\text { Extended family - through to second cousins and } \\
\text { non-blood 'relatives' }\end{array}$ \\
\hline
\end{tabular}


inadequate funding. They may appear to meet a need but in fact act as a surrogate form of racism while absolving mainstream services of responsibility. Specialist services do not eliminate the need to remove discriminatory practices and attitudes from mainstream services. This situation is reflected in the wider debates and philosophies underpinning the provision of health care in general, and mental health care in particular, for people with learning disabilities. Cultural sensitivity is only one element of quality in service provision. The notion of 'cultural diversity' is intended to move us away from a focus on 'difference' and the consequent perception of additional burden. Managing diversity means offering a level of respect to all. It also leads to recognition that the 'majority' is not a homogeneous population but comprises a number of

\section{Box 5 Service principles and action plan for service development (adapted from Mir et al, 2001 and Cole, 2002)}

The requirements of service development include:

A strategic approach

Meaningful consultation with families, carers and community workers

Going beyond consultation to real empowerment

Developing advocacy and self-advocacy, recognising family structures that differ from those of the majority ethnic community

Appropriate publicity for and full access to all service provision

Recruitment of ethnic minority and bilingual staff at all levels and ensuring their adequate support and training

Training for all staff, to increase competence in cultural awareness, sensitivity and flexibility

Person-centered planning, acknowledging discrimination and racism and its impact on the person; drawing up support plans to empower people from ethnic communities

Accurate information about need - effective monitoring processes, patterns of use, identifying unmet need

Targeting housing and placement opportunities within ethnic communities

Commissioning single-culture treatment options, including in-patient and residential facilities, self-help groups, social and psychological therapies

Working with provider agencies that specify 'cultural competence'

Integrated services: the ideal is quality mainstream services sensitive to the needs of all users cultural and social communities with their own needs and aspirations.

\section{References}

Aminidav, C. \& Weller, L. (1995) Effects of country of origin, sex, religiosity and social class on breadth of knowledge of mental retardation. British Journal of Developmental Disabilities, XLI, 48-56.

Azmi, S., Hatton, C., Emerson, E., et al (1997) Listening to adolescents and adults with intellectual disability in South Asian communities. Journal of Applied Research in Intellectual Disability, 10, 250-263.

Baxter, C. (1996) Sex education: ethnically sensitive services to people with learning disabilities. Tizard Learning Disability Review, 1, 1-6.

Bhugra, D. (2002) Assessing psychiatric problems in ethnic minority patients. Practitioner, 246, 147-163.

Bittles, A. H. (2001) Consanguinity and its relevance to clinical genetics. Clinical Genetics, 60, 89-98.

Butt, J. \& Mirza, K. (1996) Social Care and Black Communities. London: HMSO.

Chakraborty, A. \& McKenzie, K. (2002) Does racial discrimination cause mental illness? (editorial). British Journal of Psychiatry, 180, 475-477.

Channabasavanna, S. M., Bhatti, R. S. \& Prabhu, L. R. (1985) A study of attitudes of parents towards the management of mentally retarded children. Child Psychiatry Quarterly, 18, 85-92.

Cheng, P. \& Tang, C. S. (1995) Coping and psychological distress of Chinese parents of children with Down's Syndrome. Mental Retardation, 33, 10-20.

Cole, A. (2002) Developing and Improving Services to Meet the Mental Health Needs of People with Learning Disabilities: A Workbook for Commissioners and Managers in Mental Health and Learning Disability Services. London: Institute for Applied Health and Social Policy, King's College.

Cross, T. L., Bazron, B. J., Dennis, K. W., et al (1989) Towards a Culturally Competent System of Care. Washington, DC: Child and Adolescent Service System Program Technical Assistance Center.

Davis, H. \& Rushton, R. (1991) Counselling and supporting parents of children with developmental delay: a research evaluation. Journal of Mental Deficiency Research, 35, 89-113.

de Zulueta, F. (1990) Bilingualism and family therapy. Journal of Family Therapy, 12, 255-265.

Edgerton, R. B. (1984) Anthropology and mental retardation: research approaches and opportunities. Culture, Medicine and Psychiatry, 8, 25-48.

Emerson, E. (1997) Is there an increased prevalence of severe learning disabilities among British Asians? Ethnicity and Health, 2, 317-321.

Falicov, C. J. (1995) Training to think culturally: a multidimensional comparative framework. Family Process, 34, 373-387.

Farooq, S. \& Fear, C. (2003) Working through interpreters. Advances in Psychiatric Treatment, 9, 104-109.

Fatimilehin, I. A. \& Nadirshaw, Z. (1994) A cross-cultural study of parental attitudes and beliefs about learning disability (mental handicap). Mental Handicap Research, 7, 202-227.

Fernando, S. (1989) Race and Culture in Psychiatry. London: Routledge.

Gilbert, L., Nicholl, J., Alex, S., et al (1996) Ethnic differences in the outcome of serum screening for Down's Syndrome. $B M J, 3,94-95$

Jaber, L., Halpem, G. J. \& Shohat, T. (2000) Trends in the frequencies of consanguineous marriages in the Israeli Arab community. Clinical Genetics, 58, 106-110.

Karlsen, S. \& Nazroo, J. Y. (2002) Agency and structure: the impact of ethnic identity and racism on the health of ethnic minority people. Sociology of Health and Illness, 24, 1-20.

Katbamna, S., Bhakta, P., Ahmad, W., et al (2002) Supporting South Asian carers and those they care for: the role of the primary care team. British Journal of General Practice, 52, 300-305. 
McDonagh, P. (2000) Diminished men and dangerous women: representations of gender and learning disability in early- and mid-nineteenth-century Britain. British Journal of Learning Disabilities, 28, 49-53.

McGrother, W., Bhaumik, S., Thorpe, C. F., et al (2002) Prevalence, morbidity and service need among South Asian and White adults with intellectual disability in Leicestershire, UK. Journal of Intellectual Disability Research, 46, 299-309.

Mir, G., Nocon, A., Ahmad, W., et al (2001) Learning Difficulties and Ethnicity. London: Department of Health.

Nadirshaw, Z. (1997) Cultural issues. In Adults with Learning Disabilities: A Practical Approach for Health Professionals (eds J. O’Hara \& A. Sperlinger), pp. 139-153. Chichester: John Wiley \& Sons

O'Hara, J. \& Martin, H. (2003) Parents with learning disabilities: a study of gender and cultural perspectives from East London. British Journal of Learning Disabilities, 31, 18-24.

Ramey, C. T., Stedman, D. J., Borders-Petterson, A., et al (1978) Predicting school failure from information available at birth. American Journal of Mental Deficiency, 82, 525-534.

Raval, H. (1996) A systemic perspective on working with interpreters. Clinical Child Psychology and Psychiatry, 1, 29-43.

Shah, R. (1992) The Silent Minority: Children with Disabilities in Asian Families. London: National Children's Bureau.

Sperlinger, A. (1997) Introduction. In Adults with Learning Disabilities: A Practical Approach for Health Professionals (eds J. O'Hara \& A. Sperlinger). Chichester: John Wiley \& Sons.

Sue, D. W. \& Sue, D. (1999) Counseling the Culturally Different: Theory and Practice (3rd edn). New York: John Wiley \& Sons

Walsh, P. N. \& Heller, T. (2002) Health of Women with Intellectual Disabilities. Oxford: Blackwell Science.

\section{Multiple choice questions}

1 Learning disability is:

a easily diagnosed when IQ testing is administered in a culturally blind way

b more prevalent in South Asian communities

c not recognised in developing countries

d easier to accept for parents from ethnic minority communities

e often the product of consanguineous marriages.

2 People with learning disabilities from ethnic minority communities:

a do not have a strong ethnic identity

b fail to observe their own cultural and religiou practices

c experience discrimination due to racism and disability

$\mathrm{d}$ often come from dysfunctional extended families

e seldom marry and have children.
3 Carers from ethnic minority communities:

a are more likely to be receiving specialist services

$\mathrm{b}$ are just as disadvantaged as their White peers

c often receive practical and social support from their religious faith

$\mathrm{d}$ prefer to have their child with learning disabilities looked after in a local residential community home

e often believe in a spiritual explanation for their child's condition.

4 Working with interpreters:

a is not necessary if someone in the family speaks English

b may lead the clinician to feel disempowered

c is a luxury that the NHS cannot afford

d requires training

e allows easier access to the patient's mental state.

5 Delivering culturally sensitive health care means:

a matching the patient to a clinician of the same ethnic/ cultural background

$\mathrm{b}$ treating ethnic minority communities the same as everyone else

c developing specialist services

d using a 'cultural lens' in developing mainstream services

e realising that equal access is not the same as equal treatment.

\section{INVITED COMMENTARY ON Learning disabilities and ethnicity}

In her article, $\mathrm{O}^{\prime}$ Hara (2003, this issue) has concisely addressed the multitude of complex issues relating to ethnicity in people with learning disabilities, to their carers and to provision for services. The article brings out the interplay between culture, race, ethnicity and learning disability, using an interactional model.

Learning disability and ethnicity have hitherto been neglected areas of service delivery, audit and research, with only a few exceptions. The White 